\title{
MULTIFUNCTIONAL COAGULANTS BASED ON HIDROCARBOALUMINATES CALCIUM
}

\author{
Ekaterina Viktorovna Sizyakova', Pavel Vladimirovich Ivanov ${ }^{1}$ \\ 1 Saint-Petersburg Mining University, Vasilyevsky Island 21st line, 2, 199106 Saint-Petersburg, Russia, \\ e-mail: ip@spmi.ru
}

Received: 2016.12 .20

Accepted: 2017.01.06

Published: 2017.03.01

\begin{abstract}
The article describes harmful factors from the environmental point of view that accompany almost all stages of the production of non-ferrous metals. Due to the fact that this industry requires large volume of water, these factors require special attention when cleaning wastewater. The contamination of wastewater by non-ferrous metallurgy is characterized by metal ions, particulate pollutants, acids, SAS, etc. A common feature of all these substances is harmfulness, however, they are often very aggressive and toxic. The article focuses on the possible use of hidrocarboaluminates calcium as an active ion exchanger for cleanup wastewater metallurgical production.
\end{abstract}

Keywords: hidrocarboaluminates calcium, water treatment, coagulant, ion exchanger

\section{INTRODUCTION}

Recently, the use of new materials in the manufacturing process of various construction and composite materials, particularly calcium and magnesium aluminocarbonates, has been becoming more and more important, while the most perspective is calcium hydrocarboaluminate (CHCA) $4 \mathrm{CaO} \cdot \mathrm{Al}_{2} \mathrm{O}_{3} \cdot \mathrm{mCO}_{2} \cdot 11 \mathrm{H}_{2} \mathrm{O}$ [Sizyakov 1983, Sizyakova 2006].

Calcium hydrocarboaluminate (CHCA) is widely known in the field of cement chemistry [Korneev et al. 1986, Milovanov 1971, Turskiy and Filippov 1967, Zapolsky and Baran 1987, Beloglazov and Vorobiov 2000, Sizyakova and Beloglazov 2000, Babenkov 1977, Veytser and Mints 1975]. It slowly crystallizes in the natural process of hardening of cement stone over several months at low temperature [Korneev et al. 1986, Milovanov 1971, Turskiy and Filippov 1967, Zapolsky and Baran 1987]. To study its properties, the method of CHCA synthesis was developed in water medium at a temperature below $18^{\circ} \mathrm{C}$ (usually $1-5{ }^{\circ} \mathrm{C}$ ) exposure of the mixture of the essential components 4-6 months [Sizyakov 1983].

Professor V.M. Sizyakov was first to prove the possibility and defined the conditions of $\mathrm{CHCA}$ synthesis in strong electrolyte medium under the conditions of alumina production (instead of keeping in water medium for several months) [Dosch and Zur Strassen 1967, Klimentenok 2002].

CHCA has a layer-like structure based on the molecules of calcium hydroaluminate, water, ionic cluster $\mathrm{CO}_{3}^{2}$ and active $\mathrm{OH}$ exchange enabled cluster.

\section{THE STUDY AREA}

In the process of transforming unstable hexagonal CHCA lattice into a stable cubic lattic of tricalcium hydroaluminate $3 \mathrm{CaO} \cdot \mathrm{Al}_{2} \mathrm{O}_{3} \cdot 6 \mathrm{H}_{2} \mathrm{O}$ there are good conditions for active capture of silica from the solutions of the alumina production. Besides, due to superb degree of purification achieved during this process, the amount of siliceous module of aluminate solutions desilicated with the help of CHCA amounts to 4000 units. This method of desilication is considered the base of high grade alumina production based on lowquality domestic raw materials [Sizyakova 2006].

Since the early 90s V.M. Sizyakov has been supervising the works conducted by Department of Metallurgy at the National Mineral Resources 
University (Mining University) and aimed at increasing the area of use of CHCA in various sectors, particularly in the capacity of an active ion exchanger for purification of wastewater of metallurgy production [Sizyakova 2006, Sizyakova 2006, Korneev et al. 1986].

Fresh water is used almost in any non-ferrous metal production facility. The contamination of wastewater caused by the non-ferrous industry is characterized by metal ions, particulate pollutants, acids, SAS, etc. The common feature of all these substances is harmfulness, however, they are often very aggressive and toxic [Milovanov 1971, Turskiy and Filippov 1967]. Specific water consumption for production of different products are given in Table 1.

The clarifying agents used in such production facilities must be effective while also economical and safe to use. Thus, ferriferous, aluminic and mixed coagulants are of utmost importance in terms of industrial wastewater purification [Milovanov 1971, Turskiy and Filippov 1967, Zapolsky and Baran 1987].

Studies on the possibility of using "traditional" CHCA obtained in the industrial complex of "Pikalyovsky Glinozem" by means of V.M Sizyakov method in the capacity of a coagulant in purification of natural water and wastewater began as early as in 1996 at the National Mineral Resources University in conjunction with the state owned enterprise "Engineering Center Vodokanal" [Beloglazov and Vorobiov 2000, Sizyakova and Beloglazov 2000].

Experiments on the use of CHCA in the capacity of an ion exchanger for wastewater purification were carried out by the workers from the National Mineral Resources University and "Engineering Center Vodokanal" at a number of Russian enterprises including those of electroplating industry.

Table 1. Specific water consumption for production of different products

\begin{tabular}{|c|c|c|c|}
\hline \multirow{2}{*}{ Product } & \multicolumn{2}{|c|}{$\begin{array}{c}\text { Specific water consumption, } \\
\mathrm{m}^{3} / \mathrm{t}\end{array}$} & \multirow{2}{*}{$\begin{array}{c}\text { The discharge } \\
\text { of waste } \\
\text { water, } \mathrm{m}^{3} / \mathrm{t}\end{array}$} \\
\cline { 2 - 3 } & All & $\begin{array}{c}\text { Including } \\
\text { fresh }\end{array}$ & 105 \\
\hline Lead & 324 & 83 & 164 \\
\hline Zinc & 396 & 155 & 153 \\
\hline Copper & 646 & 157 & 283 \\
\hline Nickel & 2448 & 374 & 1484 \\
\hline Tin & 6190 & 1411 & 2899 \\
\hline Molybdenum & 6235 & 3438 & \\
\hline
\end{tabular}

\section{RESULTS}

The results of these experiments showed high activity of CHCA. Being a multifunctional coagulant, $\mathrm{CHCA}$ is effective in purifying water from heavy-metal ions, SAS, and organic matter. Disposal of wastewater produced by metallurgy industry into natural water bodies is one of the factors of contamination of water basins in industrial regions. The water becomes unpotable due to unbalanced natural ecosystems. Besides, purification of such water requires significant expenses.

Facilities located within cities frequently dispose wastewater into municipal sewerage, but its purification system is not designed to process heavy metals. Multi-year research has proven aluminium salts to be the most effective non-organic agents due to hydroxide formed during their hydrolysis. The main obstacle for their wide-spread use is high content of residual aluminium, narrow $\mathrm{pH}$ range where they are most active and reduced activity at low temperatures.

The use of CHCA in the capacity of an ion exchanger allows to significantly increase the working $\mathrm{pH}$ range. The residual aluminium content in water in this case was found to be much lower than the maximum allowable content $(0.5$ $\mathrm{mg} / \mathrm{dm}^{3}$ ). CHCA may be used for purification of wastewater within $\mathrm{pH}$ index range of 6 to 12 with aluminium content not exceeding the maximum permissible concentration (Picture 1).

Also studies have been conducted on the adsorptive capacity of calcium hydrocarboaluminate ions $\mathrm{Al}, \mathrm{Fe}, \mathrm{Cu}, \mathrm{Cr}, \mathrm{Pb}$ and $\mathrm{Ni}$. Since in real conditions the time of passing of industrial water in the reactor $-20 \mathrm{~min}$. or more, conducted a study of residual aluminum content depending on time since being placed in water.

The figure shows that the time during which the residual content of aluminum is minimal, is equal to 60 minutes. But after 20 minutes. it is 5 times lower than the maximum permissible concentration. The data show that CHCA is not a coagulant in the classical sense of the coagulation process (as a process of consolidation of the particles in the dispersed system with their adhesion [Babenkov 1977, Veytser and Mints 1975]). Functions of CHCA are more complicated:

- ion exchanger (selects in a solution $\mathrm{OH}^{-}$ions, the depth of ion exchange is $80 \%$ );

- adsorbent of heavy metal ions due to the large active surface $-30 \mathrm{~m}^{2} / \mathrm{g}$ (according to manufacturer);

- weighting of the precipitate. 


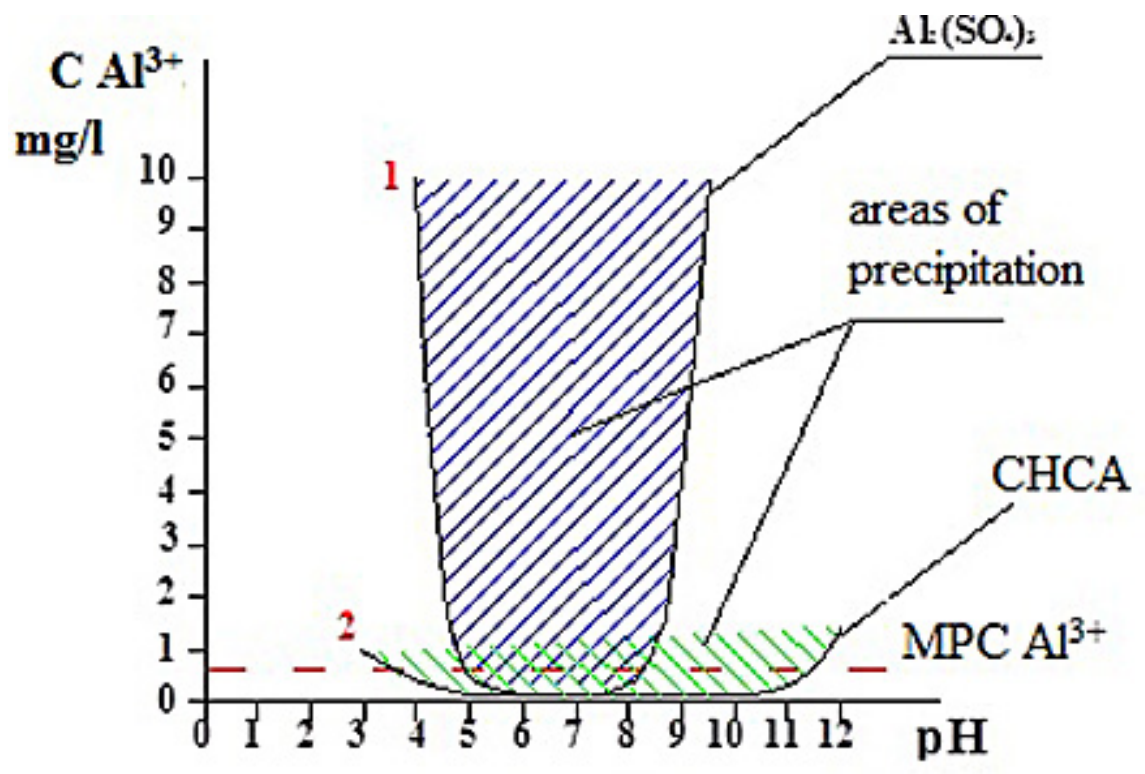

Figure 1. Residual aluminium concentration in water depending on hydrogen index: for coagulant $\mathrm{Al}_{2}\left(\mathrm{SO}_{4}\right)_{3}$ (line 1), for CHCA (line 2)

Adsorptive capacity of calcium hydrocarboaluminate for heavy metal ions (copper, chromium, nickel, lead, iron) was determined on water samples from electroplating wastewater, treated by the method of trial coagulation using iron sulfate (II), calcium hydrocarboaluminate and polyacrylamide as the flocculant (Figures 3-7.). The metal content was determined by atomic adsorption analysis.

A number of laboratory studies and pilot tests has been conducted during which the possibility of using hydrocarboaluminate as an effective ion exchanger for wastewater purification was conceptually determined. Data on the residual content of ions of impurity metals are shown in Table 2.

\section{CONCLUSIONS}

The test results showed that, in comparison with aluminium sulphate which is widely used as a coagulant, calcium carboaluminate has a number of advantages as follows: higher purification qualities, lower residual $\mathrm{Al}$ content in purified water and short purification period (approximately 20 minutes).

All the components of the proposed coagulant are allowed for use, introduction of the coagulant into an existing plants does not require the reconstruction of current wastewater treatment facilities, the waste from purification may be used as a mineralizing additive in cement production.

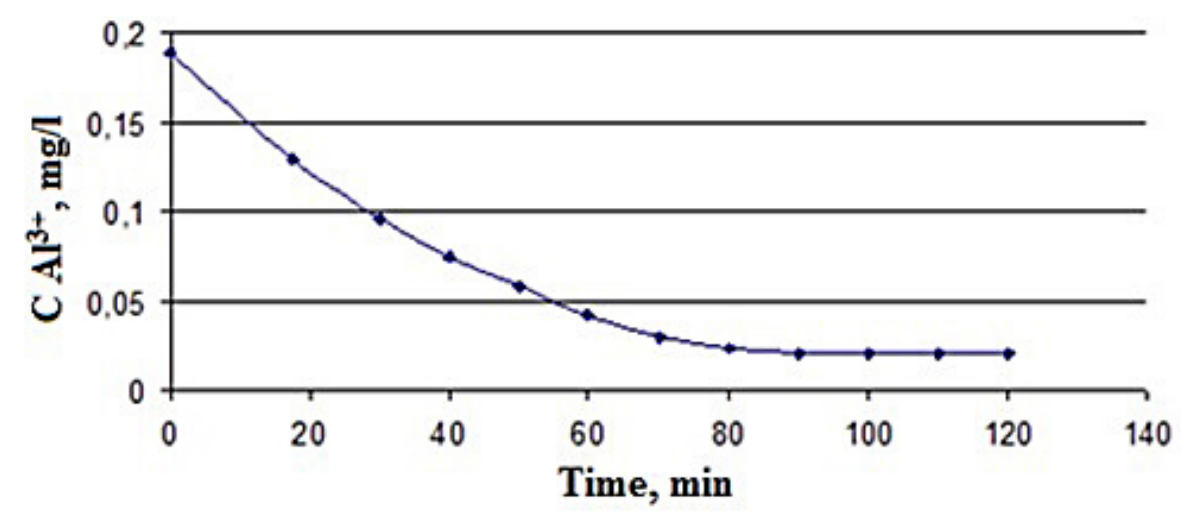

Figure 2. Residual aluminium concentration in water at $\mathrm{pH}=7.78$ depending on time 


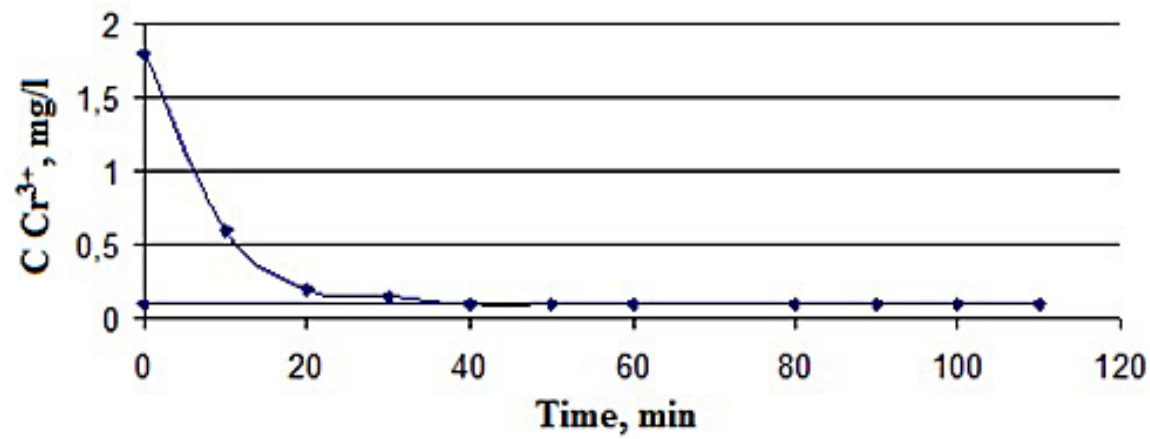

Figure 3. Residual chrome concentration in water depending on time

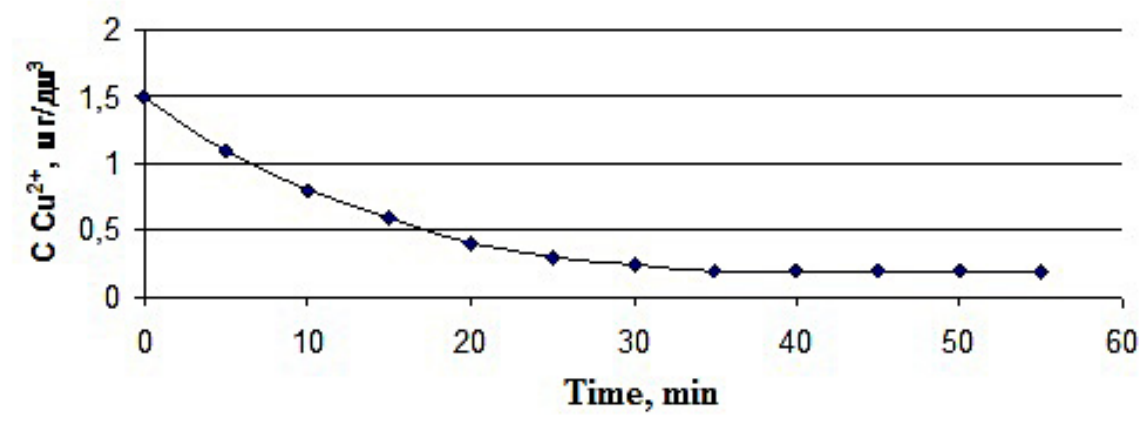

Figure 4. Residual copper concentration in water depending on time

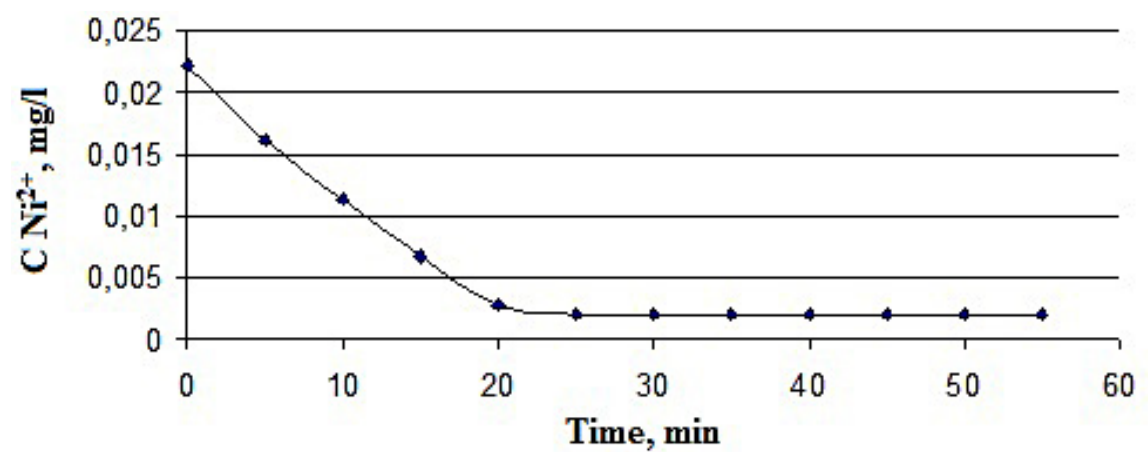

Figure 5. Residual nickel concentration in water depending on time

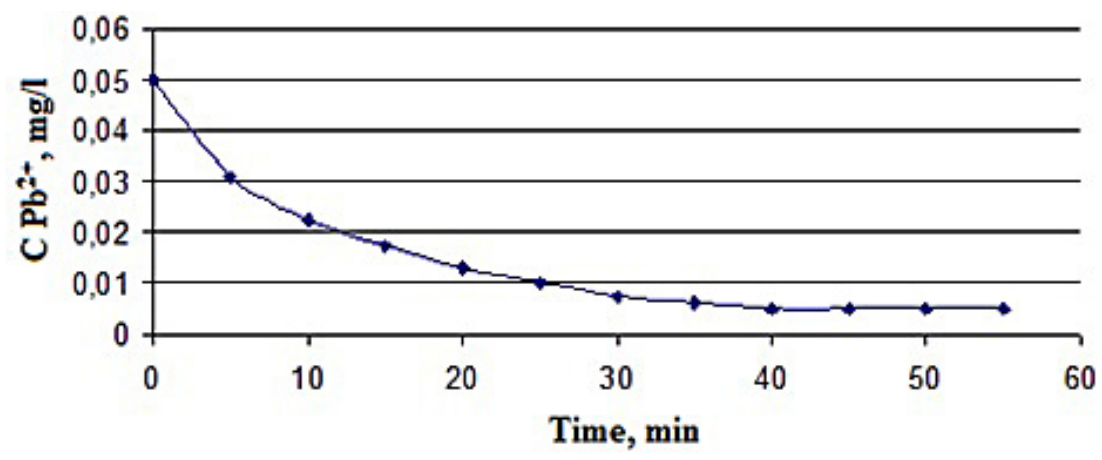

Figure 6. Residual lead concentration in water depending on time 


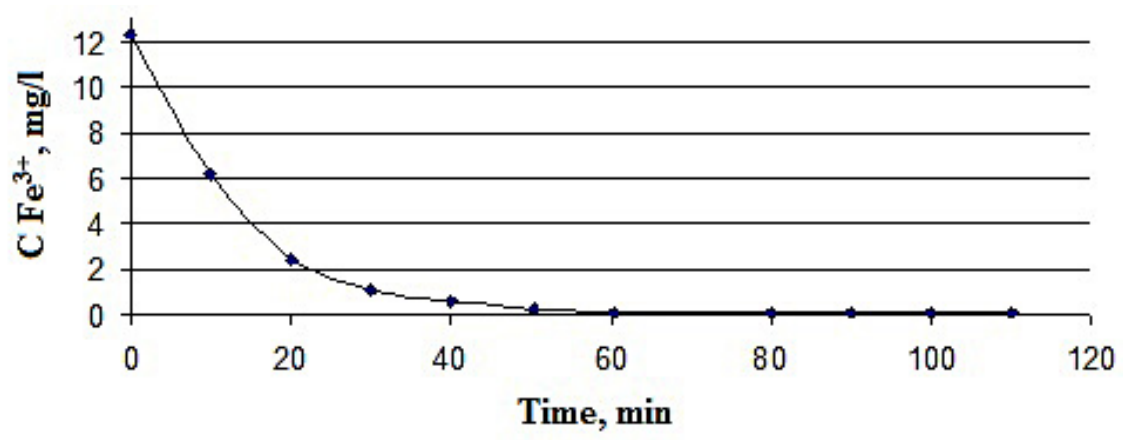

Figure 7. Residual iron concentration in water depending on time

Table 2. The residual content of ions of impurity metals in the water after acadiamarine the content of ions of impurity metals in water after cleaning

\begin{tabular}{|c|c|c|c|c|c|c|c|c|}
\hline \multirow{2}{*}{ Time. min. } & \multicolumn{8}{|c|}{ Content of elements in water. $\mathrm{mg} / \mathrm{l}$} \\
\hline & $\mathrm{Al}$ & $\mathrm{Cr}$ & $\mathrm{Fe}$ & $\mathrm{Ni}$ & $\mathrm{Pb}$ & $\mathrm{Zn}$ & $\mathrm{Cu}$ & $\mathrm{Sn}$ \\
\hline Initial sol. & 3.75 & 1.5 & 0.25 & 0.3 & 0.008 & 0.6 & 0.15 & 0.008 \\
\hline 20 & 0.25 & 0.07 & 0.025 & 0.08 & 0.001 & 0.003 & 0.03 & 0.001 \\
\hline 40 & 0.025 & 0.07 & 0.015 & 0.01 & 0.00 & 0.003 & 0.03 & 0.001 \\
\hline 60 & 0.025 & 0.07 & 0.005 & 0.01 & 0.00 & 0.003 & 0.03 & 0.001 \\
\hline 120 & 0.025 & 0.07 & 0.005 & 0.01 & 0.00 & 0.003 & 0.03 & 0.001 \\
\hline
\end{tabular}

\section{REFERENCES}

1. Beloglazov I.N., Vorobiov A.G. 2000. Metallurgical technologies and ecology. Ore and metals, Moskow.

2. Babenkov E.D. 1977. Water treatment coagulants. Science, 355.

3. Dosch W., Zur Strassen H. 1967. Zem.Klark-Gips, 20, 392-401.

4. Korneev V.I., Sizyakov V.M., Andreev V.V. 1986. Improving the quality of alumina and by-products in the processing of nepheline. Metallurgy, 115.

5. Milovanov L.V. 1971. Treatment and use of wastewater enterprises of nonferrous metallurgy. Metallurgy, 383.

6. Sizyakova E.V. 2006. Expanding the range of products when complex processing of nepheline based on the use of hydrocarboncontaminated calcium. Proceedings of the Mining Institute. New technologies in metallurgy, chemistry, enrichment and the environment, 169, 185-190.

7. Sizyakova E.V. 2006. On the role of hydrocarboncontaminated calcium in improvement of technol- ogy of production of alumina from nepheline. Proceedings of the Mining Institute. New technologies in metallurgy, chemistry, enrichment and the environment, 169, 178-184.

8. Turskiy Y.I. Filippov I.V. 1967. The industrial wastewater treatment. Chemistry, 330.

9. Veytser Y.I., Mints D.M. 1975. High molecular wezight flocculants in water treatment processes. Stroyizdat, 191.

10. Zakirov S.N. 1988. Multidimensional and multicomponent filtration. Nedra, 334.

11. Zapolsky A.K., Baran A.A. 1987. Coagulants and flocculants in water treatment processes. Chemistry, 204.

12. Klimentenok G.G. 2002. Ph.D. Thesis, StPGMI (TU), Saint-Petersburg.

13. Sizyakov V.M. 1983. Doctoral dissertation, LGI, Leningrad.

14. Sizyakova E.V., Beloglazov I.N. 2000. The use of a multifunctional coagulant for wastewater treatment of industrial enterprises. Proc. International Scientific Conference Ecological and Hydrometeorological Problems of Large Cities And Industrial Zones, 146. 